04. - 07. Mai 2016

\title{
Mitgliederversammlungen auf dem 97. Deutschen Röntgenkongress
}

(unter Vorbehalt zeitlicher Änderungen, Stand 27.1.2016)

\begin{tabular}{|c|c|c|}
\hline Donnerstag, 05.05.2016 & $17: 30-19: 00$ & $\begin{array}{l}\text { Mitgliederversammlung der Deutschen Röntgen- } \\
\text { gesellschaft ( DRG) }\end{array}$ \\
\hline Mittwoch, 04.05.2016 & $16: 30-17: 30$ & $\begin{array}{l}\text { Mitgliederversammlung der Deutschen Gesell- } \\
\text { schaft für Interventionelle Radiologie (DeGIR) }\end{array}$ \\
\hline Donnerstag, 05.05.2016 & $13: 30-14: 00$ & $\begin{array}{l}\text { Mitgliederversammlung der Vereinigung Medizi- } \\
\text { nisch-Technischer Berufe in der DRG (VMTB) }\end{array}$ \\
\hline
\end{tabular}

\section{Mitgliederversammlungen der AGen der DRG}

Zur ordentlichen Mitgliederversammlung der unten aufgeführten Arbeitsgemeinschaften der Deutschen Röntgengesellschaft, Gesellschaft für Medizinische Radiologie e.V (DRG), lädt der jeweilige Vorstand die Mitglieder der jeweiligen Arbeitsgemeinschaften hiermit herzlich ein.

\begin{tabular}{|c|c|c|}
\hline \multirow[t]{5}{*}{ Mittwoch, 04.05.2016 } & $15: 30-16: 30$ & AG Physik und Technik (APT) \\
\hline & 18:00 -19:00 & AG Kopf-/Halsdiagnostik \\
\hline & 18:15-19:15 & $\begin{array}{l}\text { AG Bildgebende Verfahren des Bewegungsappa- } \\
\text { rats }\end{array}$ \\
\hline & $18: 30-19: 30$ & AG Gastrointestinal-/Abdominaldiagnostik \\
\hline & $18: 30-19: 30$ & AG Informationstechnologie (AGIT) \\
\hline Donnerstag, 05.05 .2016 & $09: 45-10: 45$ & AG Herz- und Gefäßdiagnostik \\
\hline \multirow[t]{7}{*}{ Freitag, 06.05.2016 } & 09:45 -10:45 & AG Thoraxradiologie \\
\hline & $12: 15-13: 15$ & $\begin{array}{l}\text { AG Diagnostische Radiologie arbeits- und umwelt- } \\
\text { bedingter Erkrankungen (DRauE) }\end{array}$ \\
\hline & $12: 15-13: 15$ & AG Ultraschall \\
\hline & $17: 00-18: 00$ & AG Methoden \& Forschung \\
\hline & $18: 15-19: 15$ & AG Onkologische Bildgebung \\
\hline & $18: 15-19: 15$ & AG Uroradiologie / Urogenitale Bildgebung \\
\hline & $18: 45-19: 45$ & AG Mammadiagnostik \\
\hline Samstag, 07.05.2016 & $10: 40-11: 40$ & AG Pädiatrische Radiologie \\
\hline
\end{tabular}

